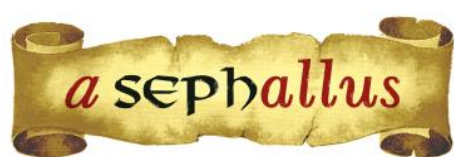

Revista aSEPHallus de Orientação Lacaniana

Núcleo Sephora de Pesquisa sobre o Moderno e o Contemporâneo

ISSN 1809 - $709 \mathrm{X}$

\title{
Sobre as selfies com os mortos: o estatuto da imagem da morte na atualidade
}

\author{
Maria Josefina Medeiros Santos \\ Doutoranda em Teoria Psicanalítica pela Universidade \\ Federal do Rio de Janeiro (Bolsista da CAPES) \\ Mestre em Psicologia com ênfase em Estudos Psicanalíticos pela \\ Universidade Federal de Minas Gerais \\ Psicóloga Clínica e Bacharel em Psicologia pela Universidade Federal de Minas Gerais. \\ E-mail: mariamedeirospsi@yahoo.com.br
}

\begin{abstract}
Resumo: Este artigo busca investigar o fenômeno contemporâneo da amplificação da captura, visualização e compartilhamento de imagens gráficas da morte pela internet, visando apreender a que se deve essa maneira de lidar com tal sorte de imagem na qual impera a obscenidade. Empreendemos esforços no sentido de elucidar o porquê desse olhar despudorado, buscando articular esse fenômeno tanto à ideia de uma suposta perversão generalizada, quanto à suposição de que o referido fenômeno seja apenas mais um índice do rebaixamento do pacto simbólico e de todas as consequências a ele vinculados.
\end{abstract}

Palavras-chave: morte; imagem; perversão; declínio da ordem simbólica.

\begin{abstract}
About the selfies with the dead: The status of the image of death in the current days
The article aims to investigate the contemporary phenomenon of the broad capture, visualization and sharing of graphic images of death on the internet, trying to apprehend the motives behind this way of dealing with this kind of image in which obscenity prevails. We make an effort to clarify the reasons of this lack of compunction, trying to articulate this phenomenon to the idea of a presumed generalized perversion and also to the supposition that the referred phenomenon is just another indication of the demotion of the symbolic pact and every consequence that is linked to it.
\end{abstract}

Key-words: death; image; perversion; decline of the symbolic order.

Sur les "selfies" avec les morts: le status de l'image de la mort de nos jours

Ce travail cherche a investiguer le phénomène contemporain de l'amplification de la capture, de la visualisation et du partage de photographies de la mort sur internet, visant comprendre ce qui motive cette manière de faire face a des images dans lesquelles l'obscenité est prevalente. Nous nous efforçons a élucider les raisons pour um tel manque de pudeur en cherchant à articuler ce phénomène a l'idée d'une possible perversion géneralisée et aussi a la supposition selon laquelle ledit phénomène n'est qu'une autre indication du rabaissement du pacte symbolique et de toutes les conséquences qui lui sont liées.

Mots-clés: mort; image; perversion; déclin de l'ordre symbolique. 


\title{
Sobre as selfies com os mortos: o estatuto da imagem da morte na atualidade
}

\author{
Maria Josefina Medeiros Santos
}

\section{I - Sobre a morte}

A morte, a despeito do modo como é concebida em diferentes culturas, não raro é tratada com deferência e respeito. Desde tempos longínquos, a morte surge como um fenômeno que causa mal-estar ao homem, não sendo fortuita a mobilização de recursos simbólicos, como rituais e celebrações religiosas, para apaziguar a angústia que amiúde a acompanha. Desse modo, a morte, uma das facetas mais íntimas do real, convoca-nos certa solenidade.

Contudo, atualmente, observamos certos fenômenos de cultura que nos levam a questionar o estatuto da morte na contemporaneidade, mais precisamente da imagem gráfica da morte. Tais fenômenos se relacionam à obscenidade escancarada na qual a morte é fotografada e filmada e, em seguida, exibida e compartilhada pela internet com o auxílio das redes sociais.

É inegável que a morte causa certa curiosidade. O próprio termo "curiosidade mórbida" já revela que há um profundo anseio em saber o que se passa com o corpo morto. Em um livro recémlançado no Brasil, intitulado Curiosidade Mórbida - A ciência e a vida secreta dos cadáveres (2015), da psicóloga americana Mary Roach, podemos constatar a importância do cadáver no avanço de pesquisas médicas e científicas. Roach revela que, ao longo da história, os cadáveres foram usados das mais diversas formas, desde cobaias nas primeiras guilhotinas da França até em pesquisas que investigavam os efeitos de viagens espaciais no corpo humano, o que fez com que os cadáveres fossem os primeiros tripulantes a navegar em foguetes da NASA.

Ao trazermos essa discussão para o âmbito metapsicológico, não podemos deixar de trabalhá-la a partir do conceito de pulsão escópica e escopofílica. Ou seja, todos esses experimentos possibilitam a satisfação pulsional por meio do olhar e da investigação do corpo morto. Nesses casos, portanto, há algo relativo ao saber e ao desejo de saber que está em jogo, dinâmica bastante distinta da que pretendemos investigar.

No caso da viralização de imagens extremamente gráficas da morte pela internet, pode-se pensar que não há algo concernente ao desejo de saber sobre a morte, ou melhor, não há nada relativo a um ímpeto investigativo e científico cernidos nessa mostração. Partimos da premissa de que o amplo compartilhamento e visualização de imagens que retratam a morte em toda a sua crueza, violência e opacidade se relaciona sobremaneira ao fato de que vivemos em uma sociedade soterrada pelo império das imagens, sendo a imagem gráfica da morte apenas mais uma entre uma infinidade de outras.

Para que essa hipótese se torne mais clara, serão trazidos alguns exemplos recentes que retratam esse ponto de investigação. Após resgatá-los, buscaremos realizar uma construção teórica que tente vislumbrar a que se deve esse modo de relação com a imagem da morte, tentando articulá- 
lo com as ideias referentes à perversão generalizada e ao rebaixamento do pacto simbólico, alinhavando-o, também, com as noções referentes ao "supersocial" e à "ordem de ferro".

\section{II - Selfies com a morte: perversão generalizada ou desordem simbólica?}

A morte de Eduardo Campos, em agosto de 2014, nos fez observar um fenômeno que, ainda que não fosse inédito, causou bastante incômodo. Em seu velório não foi incomum que visitantes parassem em frente ao seu caixão e, sorrindo, registrassem uma selfie. Ainda que esse tipo de atitude tenha sido bastante criticada nas redes sociais, várias pessoas assim o fizeram sem qualquer constrangimento.

No mês passado (julho de 2015), deparamo-nos com um vídeo da autópsia do cantor sertanejo Cristiano Araújo realizado pelos técnicos auxiliares de necropsia que preparavam o corpo para o velório. De acordo com os relatos feitos acerca do vídeo, os auxiliares faziam brincadeiras ao longo da gravação, filmando o corpo do cantor e a si próprios. O relato escrito do vídeo revela que uma das técnicas teria dito, ao final da gravação, para que o cantor desse "um tchauzinho" para a câmera. $\mathrm{O}$ ato desses auxiliares causou repúdio em grande parte da sociedade brasileira, levando à demissão dos envolvidos e à imputação aos mesmos de penas pelo crime de vilipêndio de cadáveres. Contudo, o vídeo tornou-se viral, sendo acessado por milhões de pessoas, desde fãs até indivíduos que sequer conheciam o cantor.

Mais recentemente, no dia oito de julho deste ano, um jovem de vinte e nove anos foi linchado em São Luís (MA). Segundo a polícia civil, ele teria tentado assaltar um bar da região quando foi rendido, amarrado nu em um poste e agredido até a morte com socos, chutes, pedradas e garrafadas. Um adolescente de dezesseis anos que teria sido seu cúmplice também foi espancado, mas conseguiu sobreviver ao se fingir de morto. Assim como no caso precedente, inúmeras fotos do homem morto foram vistas e compartilhadas, a despeito do horror e da barbaridade da imagem em questão.

Escolhemos resgatar apenas esses três exemplos, mas o que não faltam são casos semelhantes. Há, de fato, um sem fim de imagens extremamente gráficas de acidentes, homicídios, atropelamentos, etc., que são vistas e compartilhadas com o auxílio das redes sociais por milhões de pessoas mundo afora. Diante do exposto, questionamos acerca da ausência de constrangimento por parte das pessoas que visualizam essas imagens e, frequentemente, incitam que outros as vejam. Qual é a dinâmica em questão nesses casos? Será que há um gozo voyeurista e sádico que permeia cada vez mais a nossa sociedade? Será que é possível dizer que esses indivíduos sequer registram essas imagens, denegando-as, passando ao largo do mal-estar e da angústia que cenas cruas da morte causam àqueles situados no registro do recalque, no qual a censura e o pudor constituem índices de uma regulação? Desse modo, estaríamos falamos de uma espécie de perversão generalizada ou de um rebaixamento do pacto simbólico no qual os semblantes da tradição estão em queda, e, como consequência, observamos o aumento da obscenidade, do olhar sem véu e do 
despudor avalizado e valorizado pelo supersocial? Mais adiante retomaremos essas questões. No entanto, por ora, passemos para a hipótese de que uma suposta perversão generalizada incitaria esse tipo de relação com a espetacularização da morte.

Autores da psicanálise como Birman (2007), Dunker (2010), Dufour (2013) e outros, defendem que estamos vivendo em uma época em que a perversão tornou-se generalizada, ou seja, vivenciamos um contexto no qual os laços sociais se esfacelam em razão de uma ascensão do narcisismo em detrimento do bem-estar comum. Nessa via, o outro é rechaçado e até mesmo anulado, havendo pouco espaço para a singularidade de cada um. Ainda que essa concepção nos pareça de grande valia, cabe aqui uma ressalva no sentindo de destacar que a perversão é, antes de tudo, uma estrutura clínica que se faz ouvir pelos ecos da recusa (Verleugnung), ou seja, por meio da eleição de um fetiche, pelo sadomasoquismo e por outros sintomas. Desse modo, o uso do termo "perversão generalizada" requer cautela, pois já é notório o mau uso que é feito do termo "perversão", bem como os diferentes espectros que o mesmo comporta. Afinal, não podemos nos esquecer que a perversão já foi e ainda é objeto de pesquisas nos terrenos médico, filosófico e outros. Ademais, a confusão se acentua à medida que se observa uma sobreposição entre perversão e perversidade. A perversão, enquanto estrutura clínica estabelecida pela psicanálise, não necessariamente se associa à perversidade: "perversidade não é o mesmo que perversão, muito embora, nos casos mais graves de perversão (...) podem-se detectar evidências da perversidade tanto na transferência como nas demais relações objetais" (Ferraz, 2000, p. 21). Roudinesco complementa essa ideia dizendo que:

Embora vivamos num mundo em que a ciência ocupou o lugar da autoridade divina, o corpo o da alma, e o desvio o do mal, a perversão é sempre, queiramos ou não, sinônimo de perversidade. E sejam quais forem seus aspectos, ela aponta sempre, como antigamente, mas por meio de novas metamorfoses, para uma espécie de negativo da liberdade: aniquilamento, desumanização, ódio, destruição, domínio, crueldade, gozo. (Roudinesco, 2008, p. 11)

A perversidade, portanto, se associa a uma fenomenologia, a um conjunto de manifestações vinculadas a conotações morais e valorativas. É possível pensar, dessa maneira, que o mal-entendido que ronda a perversão reside, em grande medida, em sua proximidade com perversidade.

Caso pensemos a perversão a partir de um norte estritamente metapsicológico, ou seja, resgatando-a enquanto uma estrutura clínica, não podemos deixar de resgatar alguns textos considerados nodais na teoria freudiana a esse respeito. Nos "Três ensaios sobre a teoria da sexualidade" (1905), por exemplo, Freud compreende a perversão como um desvio e uma fixação pulsional. Em "Pulsão e seus destinos" (1915), Freud nos fala das possíveis vicissitudes da pulsão (reversão ao seu oposto; retorno em direção ao próprio eu do indivíduo; repressão e sublimação). 
Nesse texto, Freud concentra-se nos dois primeiros destinos, discorrendo acerca dos dois pares de opostos comumente atrelados à perversão: sadismo-masoquismo e escopofilia-exibicionismo. Nesse sentido, Freud pontua:

A reversão afeta apenas as finalidades da pulsão. A finalidade ativa (torturar, olhar) é substituída pela finalidade passiva (ser torturado- olhado) (...). O retorno de um instinto em direção ao próprio eu do indivíduo se torna plausível pela reflexão de que o masoquismo é, na realidade, o sadismo que retorna em direção ao próprio ego do indivíduo, e de que o exibicionismo abrange o olhar para o seu próprio corpo. (Freud, 1915/1996, p. 148)

Em "Batem numa criança" (1919), por sua vez, Freud percebe em certos relatos de fantasia de seus pacientes elementos que poderiam the auxiliar a desvendar o complexo arranjo perverso. Contudo, esse estudo vai além, acabando por fornecer importantes subsídios para a clínica com neuróticos. Toda a gramática da fantasia articulada por ele naquele contexto adquire diferentes desdobramentos, permitindo a Freud importantes conclusões no tocante aos mecanismos repressivos, ao complexo de Édipo e à gênese do masoquismo.

Ainda que o referido texto tenha sido de incontestável relevância teórica, foram necessários maiores esforços de Freud para apreender a problemática referente ao masoquismo e à perversão. Nessa empreitada, o texto "O problema econômico do masoquismo" (1924) é imprescindível na medida em que apresenta o masoquismo como originário. Um ponto essencial no que se refere à perversão também foi articulado no texto "A organização sexual infantil" (1923), no qual Freud apresentou o mecanismo da recusa (Verleugnung) como o ponto central da perversão. A noção de recusa como o mecanismo de defesa da perversão frente à castração seria complementada no artigo "Fetichismo", de 1927. Neste, o autor expõe que o objeto fetiche é um substituto para o pênis da mãe, ou seja, por meio dele o perverso reconhece, mas preserva o pênis materno por meio da recusa ou denegação (a utilização desses termos em português depende da tradução que foi utilizada, bem como da editora responsável pela vinculação dos textos freudianos no Brasil).

Como podemos observar a partir desse breve recorte sobre a perversão em Freud, não é tão óbvia a associação entre a perversão e uma suposta hipertrofia da mesma na atualidade. Afinal, os textos basilares do autor sobre a perversão se concentram na dinâmica pulsional, na fantasia, na defesa representada pela recusa e no fetiche. Desse modo, como se dá o salto desses elementos até a concepção de uma perversão generalizada? Acreditamos que esse pulo teórico que levou à apropriação do conceito referente à perversão a partir de vieses que não necessariamente comportam a perversão em sua essência estrutural constitui-se como um ponto de questionamento. Acreditamos que para abordá-lo de modo mais amplo seria necessária uma extensa revisão bibliográfica, bem como uma depuração de ideias que não nos é possível por agora. Desse modo, 
prosseguiremos com essa ressalva, tentando abordar a ideia de uma "perversão generalizada" a partir de norteamentos freudianos, ainda que esses possuam limitações.

A partir de Freud, portanto, a dinâmica pulsional cernida nos opostos sadismo e masoquismo e voyeurismo e exibicionismo podem ser aqui destacados como pontos de grande relevância para pensarmos o fenômeno que pretendemos investigar, qual seja, a ampla visualização e compartilhamento de imagens gráficas da morte.

Podemos pensar que há, no caso das pessoas que filmam e compartilham essas imagens, a existência de um gozo sádico que se compraz ao ver a destruição do outro e, ao mesmo tempo - à medida que o sadismo é indissociável ao masoquismo - a possibilidade da fruição de um gozo masoquista, uma vez que as imagens em questão podem causar sofrimento. Em relação ao voyeurismo e ao exibicionismo, também é inegável que possa existir entre esse público aqueles que também satisfazem a pulsão escópica por meio do olhar e da observação do corpo morto, bem como gozam ao exibir ao outro essa imagem.

Esse raciocínio que tange tanto o sadomasoquismo quanto o exibicionismo e o voyeurismo é possível de ser incluído em nossa discussão, podendo lançar luz, entretanto, em apenas alguma parcela dos casos de indivíduos siderados pelas imagens gráficas da morte. O que buscamos sublinhar é que não se tratam necessariamente de indivíduos estruturalmente perversos, muito embora alguns deles façam uso do já citado mecanismo da recusa ou denegação (Verleugnung). É importante marcar que esse mecanismo adquiriu contornos mais elaborados ao longo da obra freudiana, principalmente a partir de um de seus últimos textos: "A divisão do ego nos processos de defesa" (1938). Neste, Freud lança mão de um caso clínico para evidenciar que é possível, a partir da ajuda de certos mecanismos, rejeitar a realidade e recusar-se a aceitar qualquer proibição, ou então, reconhecer o perigo da realidade, assumir o medo desse perigo com um sintoma e, subsequentemente, tentar desfazer-se do medo. O autor aponta, contudo, que a manutenção simultânea de uma satisfação pulsional e um respeito apropriado pela realidade tem um preço: o surgimento de uma fenda no ego, uma divisão que nunca se cura, mas que só aumenta à medida que o tempo passa.

Percebemos, por meio desse delineamento progressivo da "recusa", uma tentativa por parte de Freud de descrever um mecanismo originário de defesa perante a realidade externa, ou seja, uma recusa originária que seria o protótipo de outras recusas da realidade e também da recusa estruturalmente perversa. No texto de 1938, vislumbramos a Verleugnung como mecanismo básico do aparelho psíquico, ou seja, ela seria apenas uma das formas de denegação, não sendo possível vinculá-la, exclusivamente à perversão. Dessa maneira, é possível pensar que há uma espécie de dinâmica denegatória entre os sujeitos que visualizam e compartilham as referidas imagens, ou seja, eles sabem que é a morte que está ali em toda a sua crueza e violência, mas, ao mesmo tempo, recusam-na, pois há um perigo em reconhecê-la em sua vertente real. A partir dessa divisão, há um afrouxamento psíquico que permite ao sujeito não ter de lidar com o que está verdadeiramente em 
questão: a castração. Dessa maneira, vivem em uma lassidão que incita a obscenidade e o descontrole pulsional. Não se trata, portanto, de uma atitude estruturalmente perversa, pois não há a negação da lei através da sua transgressão, como nos ensina Lacan (1960).

Acreditamos que associado a essa dinâmica denegatória, podemos contar com a hipótese de que a questão aqui levantada pode também ser explicada por outra dinâmica na qual a liberação do gozo e a queda ou desvalorização do ideal de regulação sustentado pela metáfora paterna prevalecem. É possível pensar que vivemos em um mundo carente de balizas simbólicas, ou seja, em um contexto em que "os semblantes, verdadeiros operadores metafóricos sobre a relação do sujeito com o gozo" (Coelho dos Santos, 2014, p. 13) claudicam cada vez mais. Como resultado desse rebaixamento do pacto simbólico, observamos a elevação do contrato intersubjetivo, ou seja, do "supersocial". Este pode ser pensado como um arranjo entre os pares no qual se entrevê a submissão aos usos comuns e banais da rotina. Ou seja, há uma relação de proporção indireta: quanto mais falham os operadores simbólicos e os semblantes, mais observamos uma desregulação que se vale a partir de normas compartilhadas.

Em uma época em que a tradição, o pudor e a intimidade são cada vez mais rechaçados afinal, são resquícios dos semblantes tradicionais -, vemos, em contraposição, uma espécie de contrato social no qual todos se sentem no direito de gozar como bem quiserem, desrespeitando o outro em sua autonomia, liberdade, e, por que não, até em sua morte. Nesse sentido, falamos não de uma perversão estrutural, mas em uma perversão banal e cotidiana. Sob esse prisma, alguns sujeitos de nossa época, desde que apoiado pelos seus pares, sentem-se apoderados do direito de tudo, até mesmo de brincar com um cadáver e linchar um suspeito de assalto. É possível pensar que a viralização dessas imagens é o índice do aval entre os pares, é o supersocial em detrimento da lei simbólica.

Coelho dos Santos (2014) complementa essa ideia discorrendo acerca do gosto hipermoderno pela avaliação generalizada. Para a autora, esse anseio

(...) propaga a nova 'ordem de ferro', ditadura da transparência do sujeito a si mesmo e aos seus pares na civilização. $O$ direito ao segredo, à privacidade, à esfera íntima cede seu lugar ao imperativo de mostrar. A realidade psíquica é chamada a exibir-se no reality show dos meios de comunicação. Parece que o gozo do avaliacionismo é o crescimento do gosto pela exibição de si. (Coelho dos Santos, 2014, p. 35-36)

Aqui cabem algumas considerações relativas à chamada "ordem de ferro", que possui uma intima relação com o que já foi exposto a respeito do supersocial e do rebaixamento do pacto simbólico. É Marie-Hélène Brousse quem faz a articulação entre o que foi dito por Lacan, em uma aula de 9 de março de 1973, com a ordem de ferro na atualidade. Naquele contexto, Lacan diz que 
no discurso da civilização contemporânea o Nome-do-Pai foracluído do simbólico retorna no real das normas sociais.

Brousse interpreta essa intuição lacaniana como a substituição desse operador simbólico pela cifra, pela média, pela curva de Gauss, cujo centro é a ordem social (...) Lacan qualifica esta nova ordem social como 'ordem de ferro' (Lacan, 19731974, aula de 19/03/1974), pois ela é muito mais feroz que a interdição pelo Nomedo-Pai que dá lugar ao desejo. (Coelho dos Santos, 2014, p. 34)

E em que isso se articula com o fenômeno contemporâneo da viralização das imagens gráficas da morte? A ordem de ferro preconiza o imperativo do gozo sem interdições. Ela é correlata do superego pulsional que vocifera: "Goza!". Ainda que essa vertente pulsional do supereu não seja nenhuma novidade, aqui a percebemos com um agravante. Com a vacilação cada dia mais observável do Nome-do-Pai, os indivíduos se valem da ordem ou norma estipulada entre os pares o supersocial - para estipular o que seria "normal". Esse movimento acarreta os mais diversos problemas, pois coloca em xeque o próprio conceito de normalidade, conceito este que não pode ser pensado fora do domínio da ciência. O que observamos é que os pares estabelecem o comum acordo ou o normal, o que invariavelmente traz embaraços em uma sociedade em que o "proibido proibir" impera. Em um contexto em que há uma ditadura da exibição, de certa hipertrofia do olhar, anormais são aqueles que preservam a sua intimidade, o seu corpo e o seu pudor. Não seria equivocado dizer que, na atualidade, é percebido com estranheza pela sociedade do espetáculo aqueles que se recusam a ver o vídeo da autópsia do cantor Cristiano Araújo, bem como aqueles que se recusam a ver as fotos do acidente de carro que o matou. No esfacelamento dos semblantes tradicionais tão caros ao simbólico reinam a desordem imaginária e a sua parceria com o real sem lei.

\section{III - A morte no "Império das Imagens": reflexões e questionamentos sobre o imaginário hoje}

Diante do que foi exposto até o momento, a pergunta de Coelho dos Santos (2014) tornase basal: "Os nomes universais do real são ainda a morte, o sexo e o desamparo? Ou são nomes mais particulares e deveríamos perguntar o que é que para cada ser falante, em sua anormalidade ou em seu sintoma, configura um real traumático, impossível de suportar" (Coelho dos Santos, 2014, p. 30).

O fenômeno que aqui propusemos a investigar nos sinaliza que a morte, para vários indivíduos, não é essencialmente um dos nomes do real. Como já sinalizamos anteriormente, a imagem da morte parece ter se tornado mais uma - denegada - entre tantas outras nisso que estamos chamando "O Império das Imagens". Este é o título do VII Encontro Americano de 
Psicanálise de Orientação Lacaniana de 2015, o ENAPOL. Este tem como foco principal estudar o imaginário a partir dos novos tempos. $\mathrm{O}$ argumento do encontro nos norteia no seguinte sentido:

O último ensino de Lacan nos orienta para uma nova clínica. Certamente, a clínica estrutural não pode ser desprezada, ao contrário, ela continua sendo uma bússola para nossa prática e consequentes elaborações teóricas. Neste contexto já não se trata mais do que a imagem, bela e única, seja a que reina e localiza em seu cárcere sutil o inominável do gozo e o real. É o véu de Maya como tal, é o Império das imagens que se projeta sobre o muro da linguagem. Imagens múltiplas, fragmentadas, onipresentes, desproporcionais, intrusivas, que, sem mediação, impactam, fascinam, traumatizam, afetam subjetividades e corpos, às vezes tornando-se referências; paradoxos da época. (Diretoria Executiva do VII ENAPOL, 2014)

Esse excerto entra em consonância com o nosso ponto de investigação, ou seja, parece que não lidamos mais com tanta frequência com "a imagem bela e única, (...) a que reina e localiza em seu cárcere sutil o inominável do gozo e o real". Se antes a imagem, a estética e o belo, conferiam uma unidade e o cerceamento do gozo e do real, hoje, não raro, sinalizam o oposto, ou seja, trazem o real em cena e nos impactam, sem mediação. Creio que o argumento do VII ENAPOL e a pergunta proposta por Coelho dos Santos apontam para uma mudança no modo como o imaginário contemporâneo se configura, sendo o gozo opaco advindo com a visualização da morte apenas um índice dessa desregulação.

É inegável que essa desregulação não é universal, havendo ainda aqueles sujeitos que se angustiam com os nomes tradicionais do real, bem como sofrem diante dessa bulimia de imagens, como nos aponta Miller (1995/2006, p. 399): "Por que não admitir também outro momento no qual estamos sob o domínio de certa bulimia imaginária? Padecemos de uma absorção intensa, acelerada de imagens. De imagens de corpos".

Também podemos contar com contribuições preciosas de Miller a respeito do imaginário em "Imagem Rainha". Este texto, ainda que seja de 1997, levanta questionamentos e possibilita articulações bastante interessantes acerca do imaginário hoje. Miller introduz "a expressão imagem rainha como homóloga, no imaginário, da expressão significante-mestre no simbólico" (Miller, 1995/1997, p. 575). Nesse sentido, ele se questiona: quais são as imagens que dominam no imaginário, ao menos quando se trata da psicanálise? O autor conclui que haveria não mais que três: "Há o próprio corpo, o corpo do Outro e o falo" (Miller, 1995/1997, p. 578).

É possível pensar que na viralização de imagens gráficas da morte há a articulação dessas três imagens rainhas. Contudo, não seria inoportuna a ideia de que não há propriamente um registro dessas imagens, elas não chegam a ser significantizadas. Em muitos casos elas surgem, são vistas 
e compartilhadas como qualquer outra imagem. Sublinhamos o "em muitos casos", pois não deixamos de reiterar que, embora essas imagens não causem qualquer mal-estar em muitos indivíduos, elas continuam a afetar muitos outros. É possível defender que a ausência de registro dessas imagens se relacione, como já foi articulado, a uma dinâmica na qual a denegação torna-se o mecanismo de defesa privilegiado. Ou seja, há algo em relação ao modo como essas imagens são encaradas que sinalizam que, ainda que sejam vistas, não se quer muito saber sobre elas.

\section{IV - A posição "tradicionalista" como uma saída possível?}

Por fim, podemos nos indagar: como nós, psicanalistas, devemos nos situar frente a essa desregulação do império das imagens? Qual é o nosso papel?

Seria um movimento ingênuo nos colocarmos em uma posição exterior na qual destacamos um problema e não avaliamos a responsabilidade que a própria psicanálise possui em todo esse contexto. Miller, no IV Congresso da Associação Mundial de Psicanálise, em Comandatuba (2004), provoca-nos a pensar sobre o nosso papel diante daquilo que nos queixamos. Naquele contexto, ele afirma concordar com o uníssono de psicanalistas que proclamavam estar diante de sujeitos "desinibidos, neo-desinibidos, desamparados, desbussolados" (Miller, 2004, p. 1). Com a ironia que Ihe é particular, Miller complementa: "Ao escutá-los, eu me dizia: Ah! Sim, sim, sim! Como somos desbussolados! Como isso é verdade! (...) Então, ao escutá-los, eu me perguntava: Desde quando isso acontece, desde quando estamos todos desbussolados?" (Miller, 2004, p. 1). Assim, o autor insere a ideia de que foi a própria psicanálise que criou essa confusão. Desde que Freud abalou a moral civilizada vitoriana, apontando os sintomas por ela causados em suas histéricas, nos vimos sem o norte que aquela tradição nos propiciava.

Miller retoma uma ideia de Lacan presente em "Radiofonia" (1970) para dizer que o objeto $a$ talvez seja a nova bússola da civilização. Desse modo, percebe-se a vinculação entre o objeto $a$ no zênite da civilização e a "ordem de ferro": à medida que os ideais padecem, há uma liberação na via do gozo do objeto.

Pois então? Se assumimos a incidência e a difusão da psicanálise na atualidade, se nos responsabilizamos pelo convite feito por Freud para falarmos e, por meio da fala, desvirtuamos os preceitos da moral civilizada, qual atitude nos resta? Miller nos aponta quatro possibilidades: a reacionária, a passadista, aquela que adere ao real da ciência e a prática lacaniana. E como se configuram cada uma dessas vias? Norteando-se a partir das categorias do simbólico, do imaginário e do real. Para Miller, existem: 1) Aqueles que se valem de uma "prática reacionária da psicanálise". Seria aquele psicanalista que exalta o simbólico vinculado à tradição; 2) 0 psicanalista passadista, que julga que nada está acontecendo: "Em suma, que o inconsciente nunca morre, privilegiando por essa via refugiar-se no imaginário de uma bela indiferença" (Portillo, 2005, p. 6-7); 3) Aqueles que se aderem ao real da ciência, pelo menos assim o acreditam. Seriam os progressistas que acreditam estar em sintonia com o real da ciência. Eles tentam encontrar uma tradução neurocognitivista da 
metapsicologia freudiana e tratar o real pela via farmacológica; 4) Por fim, haveria a prática lacaniana, "ou melhor, haverá, visto que se trata de inventá-la" (Miller, 2004, p. 6), nos diz Miller. Este destaca que essa prática já está minimamente traçada a partir do último Lacan, e que é preciso que na prática lacaniana do futuro se entreveja os princípios das três práticas acima, ou seja, o princípio do "isto funciona" (Miller, 2004, p. 6).

É possível pensar que Miller aposta em uma prática a ser paulatinamente constituída a partir dos:

(...) novos reais dos quais o discurso da civilização hipomoderna dá testemunho. Ela conduz seu jogo na dimensão de um real que falha, de tal modo que a relação entre os dois sexos tornar-se-á cada vez mais impossível. Então, o um-sozinho será o standard pós-humano, o um-sozinho preenchendo questionários para receber a sua avaliação, o um-sozinho comandado por um mais-de-gozar que se apresenta em seu aspecto mais ansiogênico. (Miller, 2004, p. 7)

É possível, a partir dessa proposta de Miller, fazermos alguns questionamentos e também pontuações. Ainda que a conferência em questão tenha aproximadamente dez anos, ela ainda é bastante atual. Já colhemos os frutos desse real que falha e do crescimento do um-sozinho. Sem dúvida, vivemos no domínio das práticas avaliatórias que estimulam a mostração e a medicação. Contudo, não seria equivocado dizer que Miller traça mais o estado das coisas do que propriamente saídas possíveis frente ao desbussolamento generalizado. Ele nos indica que o gozo perverso é permitido, resta-nos saber como proceder diante disso. Ora, disso já sabemos e toda a nossa articulação prévia entra em consonância com essa ideia. Sim, é permitido, porém, o que nos resta?

Hoje em dia, poucas palavras são mais odiadas no atual contexto social e político brasileiro do que "reacionário". A ojeriza por esse termo advém da presente conjuntura política acirrada pela última eleição presidencial. Atualmente, o Brasil vive um dualismo em que as pessoas se dividem entre os "de esquerda" e os "de direita", bem como entre "reacionários" e "liberais" (ainda que se possa dizer que no Brasil não seja possível estabelecer esses binarismos, eles permeiam as discussões políticas). No Dicionário Priberam da Língua Portuguesa (Versão Online), "reacionário" possui origem na palavra francesa "réactionnaire" e é 1 . Relativo ao partido da reação ou ao seu sistema; 2. Oposto à liberdade; 3. Sectário da reação política ou social; 4. Que ou quem é muito conservador (retrógrado). Como podemos observar, a palavra "reacionário" não anda em alta conta por aqui, sendo mais interessante pensá-la a partir da vertente da tradição, afinal, o próprio Miller (2004) diz que a "prática reacionária da psicanálise" se vincula ao apego pelo simbólico e pela tradição. Desse modo, achamos mais interessante pensarmos em "prática tradicionalista da psicanálise", uma vez que, por meio dessa terminologia, nos desfazemos do estofo essencialmente político que vem sendo cada vez mais atrelado à palavra "reacionário". 
Realizou-se esse preâmbulo, pois acreditamos que essa "prática tradicionalista da psicanálise" nos é extremamente cara, sendo no mínimo curioso posicionamentos que a acusem de retrógrada ou obsoleta. Essa prática visa primordialmente uma aposta no simbólico. Associado a isso, ela se baliza nos ideais ou no que deles restaram. Se os nomes do ideal da tradição encontramse enfraquecidos (família, governo, escola e etc.), podemos trabalhar com os resquícios desses semblantes na clínica, o que não é sem efeitos.

Também não podemos nos esquecer do que diz respeito a não recusar "o real certifico e o saber no real" (Miller, 2004, p. 9) em relação aos posicionamentos pensados por Miller. Isso é fundamental, pois se articula a um chamado que sempre foi feito por Lacan e que muitos desconhecem ou se recusam a escutar. É extremamente contraproducente rechaçar os saberes científicos, uma vez que a própria psicanálise se articula como uma ciência.

\section{V - Conclusões}

De acordo com estatísticas do Instagram, no ano de 2012 foram postadas 58 fotos por segundo nesta rede social (Cardona, 2015). Hoje, em 2015, certamente essa cifra aumentou e só tende a crescer. Por mais que o termo "Império" soe incômodo para alguns - afinal, ele possui vizinhança com o termo "imperialismo" e com tudo que isso comporta (Laia, 2015) -, é inegável que vivemos siderados, solapados, soterrados por um sem número de imagens. Mais do que isso: essas imagens parecem tomar cada vez mais um lugar privilegiado, ocupando o que antes era dominado pelas referências simbólicas. O domínio das imagens, com toda a sua desordem, desarticulação e fugacidade, se imiscui de modo irrefreável na vida dos homens, reverberando nas constelações familiares, no ordenamento social, no campo amoroso, sexual e etc.

O fenômeno cultural que buscamos aqui elucidar é apenas um índice dessa desregulação que incide em nosso ordenamento simbólico. Frente aos semblantes da tradição que fracassam, e ao Nome-do-Pai que se enfraquece, encontramos sujeitos desnorteados, mais afiliados ao livre acesso ao gozo do que ao seu desejo. Organizados pela norma estabelecida pelo supersocial, estabelecem o que é permitido a partir dos seus pares, movimento que amiúde exclui o bom senso, o respeito, o pudor e a vergonha. A lei simbólica universal, que preconiza a igualdade de direitos e deveres para todos, é sobrepujada por acordos lassos (porém tirânicos) que, não raro, estimulam a obscenidade. Em uma época em que o "proibido proibir" está fora de moda, o direito ao gozo é a regra, o que incita comportamentos como a viralização de imagens gráficas da morte. Onde outrora havia um respeito e solenidade, hoje se observa um olhar sem véu.

Vivemos em um mundo em que o olhar encontra-se hipertrofiado em um contexto em que o homem não mais possui o direito à sua intimidade. Gérard Wajcman (2010), filósofo e psicanalista francês, fala da existência do "homem sem sombras", ou seja, do homem contemporâneo impedido até mesmo do direito de se esconder. Ou seja, vivemos no imperativo da transparência, do tudo falar e ver. Hoje, o homem exibe até mesmo as suas entranhas, literalmente... 


\section{Agradecimentos:}

Agradeço a minha orientadora Dra. Tania Coelho dos Santos, bem como aos membros do ISEPOL e do Núcleo Sephora de Estudo e Pesquisa.

\section{Referências Bibliográficas}

Birman, J. (2007). Mal-estar na atualidade: a psicanálise e as novas formas de subjetivação. Rio de Janeiro: Civilização Brasileira.

Coelho dos Santos, T. (2014). Do Supereu sujeitado à lei simbólica à normatividade supersocial dos corpos falantes. In Coelho dos Santos, T.; Santiago, J. \& Martello, A. (Orgs.), Os corpos falantes e a Normatividade do Supersocial (pp. 27-62). Rio de Janeiro: Cia de Freud.

Cardona, M. E. (2015). O corpo e o Selfie. Recuperado de http://oimperiodasimagens.com.br/pt/faqitems/o-corpo-e-o-selfie-maria-eugenia-cardona/.

Diretoria executiva do VII ENAPOL. (2015). Argumento. Recuperado de http://oimperiodasimagens.com.br/pt/argumento/.

Dufour, D.-R. (2013). A cidade perversa - Liberalismo e pornografia. São Paulo: Civilização Brasileira.

Dunker, C. I. L. (2010, mar.). A perversão nossa de cada dia. Revista Brasileira de Cultura, 13(144), 29-31.

Ferraz, F. C. (2008). Perversão. São Paulo: Casa do Psicólogo.

Freud, S. (1996). Três ensaios sobre a teoria da sexualidade. In J. Salomão (Trad.) Edição standard brasileira das obras psicológicas completas de Sigmund Freud (Vol. 7, pp. 119-299). Rio de Janeiro: Imago (Trabalho original publicado em 1905).

Freud, S. (1996). Pulsão e seus destinos. In J. Salomão (Trad.) Edição standard brasileira das obras psicológicas completas de Sigmund Freud (Vol. 14, pp. 129-168). Rio de Janeiro: Imago (Trabalho original publicado em 1915).

Freud, S. (2010). Batem numa criança. In Paulo Cézar de Souza (Trad.) Obras Completas (Vol. 14, pp. 293-327). São Paulo: Companhia das letras (Trabalho original publicado em 1919).

Freud, S. (1996). Organização Sexual Infantil. In J. Salomão (Trad.) Edição standard brasileira das obras psicológicas completas de Sigmund Freud (Vol. 19, pp. 177-184). Rio de Janeiro: Imago (Trabalho original publicado em 1923).

Freud, S. (1996). O problema econômico do masoquismo. In J. Salomão (Trad.) Edição standard brasileira das obras psicológicas completas de Sigmund Freud (Vol. 19, pp. 197-212). Rio de Janeiro: Imago (Trabalho original publicado em 1924).

Freud, S. (1996). Fetichismo. In J. Salomão (Trad.) Edição standard brasileira das obras psicológicas completas de Sigmund Freud (Vol. 21, pp. 151-162). Rio de Janeiro: Imago (Trabalho original publicado em 1927). 
Freud, S. (1996). A divisão do ego no processo de defesa. In J. Salomão (Trad.) Edição standard brasileira das obras psicológicas completas de Sigmund Freud (Vol. 23, pp. 305-312). Rio de Janeiro: Imago (Trabalho original publicado em 1938).

Lacan, J. (2008). O seminário, livro 7: a ética da psicanálise. Rio de Janeiro: Zahar (Trabalho original publicado em 1960).

Lacan, J. (2003). Radiofonia. Outros escritos (pp. 400-447). Rio de Janeiro: Zahar (Trabalho original publicado em 1970).

Laia, S. (2015). O que é "Império", o que são "Imagens". Recuperado de http://oimperiodasimagens.com.br/pt/faq-items/o-que-e-imperio-o-que-sao-imagens-sergiolaia/.

Magalhães, A. W. L. \& Sussuarana, A. C. (2013, mai. a out.). O espectro perverso na sociedade narcísica. Revista asEPHallus de Orientação Lacaniana, $8(16)$. Recuperado de http://www. isepol.com/asephallus/numero 16/artigo 04.html.

Miller, J.-A. (1995/1997). Lacan Elucidado - Palestras no Brasil (pp. 575-595). Rio de Janeiro: Zahar. Miller, J.-A. (2004). Conferência em Comandatuba. Recuperado de http://www.congresoamp.com/pt/template.php?file=Textos/Conferencia-de-Jacques-AlainMiller-en-Comandatuba.html.

Miller, J.-A. (1995/2006). Introducción a la Clinica Lacaniana - Conferências en España (pp. 379394). Barcelona: ELP.

Portillo, R. (2005). O declínio do Ideal, e a exigência de gozo. Latusa Digital - Revista da Escola Brasileira de Psicanálise - Rio de Janeiro, 2(16). Recuperado de http://www.latusa.com.br/pdf latusa digital 16 a1.pdf.

Roach, M. (2015). Curiosidade mórbida - A ciência e a Vida Secreta dos Cadáveres. São Paulo: Companhia das Letras.

Roudinesco, E. (2008). A parte obscura de nós mesmos: uma história dos perversos. Rio de Janeiro: Zahar.

Wajcman, G (2010). L'oeil absolu. Paris: Denoel.

Citacão/Citation: Santos, M. J. M. (mai. a out. 2015). Sobre as selfies com os mortos: o estatuto da imagem da morte na atualidade. Revista aSEPHallus de Orientação Lacaniana, 10(20), 70-83. Disponível em www.isepol.com/asephallus. doi: 10.17852/1809-709x.2019v10n20p70-83

Editor do artigo: Tania Coelho dos Santos.

Recebido/Received: 25/08/2015 / 08/25/2015.

Aceito/Accepted: 01/09/2015 / 09/01/2015.

Copyright: (C) 2013 Associação Núcleo Sephora de Pesquisa sobre o moderno e o contemporâneo. Este é um artigo de livre acesso, que permite uso irrestrito, distribuição e reprodução em qualquer meio, desde que 0 autor e a fonte sejam citados/This is an open-access article, which permites unrestricted use, distribution, and reproduction in any medium, provided the author and source are credited. 